\title{
1 Prebiotics to manage the microbial control of energy homeostasis
}

Grootaert, C.^, Marzorati, M.^, Van den Abbeele, P.^, Van de Wiele, T. and Possemiers, S. *

Laboratory of Microbial Ecology and Technology (LabMET), Ghent University, B-9000 Ghent, Belgium.

*: Corresponding author: POSSEMIERS Sam, UGent. Coupure Links 653, B-9000 Gent, Belgium. Phone: +32 926459 76, Fax : +32 926462 48. sam.possemiers@ugent.be

$\wedge$ : these authors equally contributed to the review

Key Words: Prebiotics, obesity, homeostasis, diabetes, mucosa

\begin{abstract}
The prevalence of obesity is continuously growing and has reached epidemic proportions. It is clear that current methods to combat obesity are not effective enough to reduce the problem. Therefore, further investigation is needed to develop new strategies. Recent research pointed out a potential role of the microbial community associated to the human host in controlling and influencing the energy homeostasis. According to the concept of Gastrointestinal Resource Management, this microbiota and its metabolic potential can be steered with the aim of improving host health. This review therefore focuses on the modulation of the intestinal microbiota through prebiotics with the aim to control of several aspects of metabolic homeostasis. In a first part, the importance of host-microbe cross-talk at the intestinal epithelium is discussed. Yet, energy metabolism, which includes both lipid and glucose metabolism, is also regulated by several key organs including the adipose tissue, brain, liver, muscles, pancreas and gut. Therefore, in a second part, we will discuss the microbial factors that are involved in the communication between these different tissues, and their potential management. Finally, we will give some future prospects of the use of prebiotics in an individualized treatment of metabolic disorders.
\end{abstract}


Humans and microbes co-evolved for several thousands of years. Such an interaction is so bounding that - according to the hologenome theory of evolution - the host organism and its microbiota can be considered as a holobiont, a unit of selection in evolution (Rosenberg and Zilber-Rosenberg, 2011). This complex microbiota can be seen, in economic terms, both as an asset and liability with the capability of influencing the fitness of the host (Possemiers et al., 2009).

In 2004-2005, the first reports about the effect of gut microbiota on the development of obesity and energy metabolism were published by the group of Jeffrey Gordon (Bäckhed et al., 2004; Ley et al., 2005). Since then, the microbial impact on several aspects of metabolic homeostasis was investigated (Burcelin et al., 2009; Cani and Delzenne, 2007; Maurer et al., 2009), such as the effect on lipid metabolism and atherosclerosis (reviewed by Caesar et al. (2010)), on metabolic syndrome (reviewed by Cani and Delzenne (2009); Sanz et al. (2010); Tilg (2010); Wellen and Hotamisligil (2005)) and insulin resistance and diabetes (reviewed by Delzenne and Cani (2010); Musso et al. (2011)). Although the mechanisms of action and the triggering factors are not fully understood, it is commonly accepted that the final health effect is the result of a complex interplay between various bacteria, which interact through various mechanisms with the host.

The capacity and the possibility to interfere in these complex interactions has been defined in the intuitive concept of Gastrointestinal Resource Management (GRM), i.e. the management of the complex gut microbiota and its metabolism with the aim of improving the health of the host (Possemiers et al., 2009).

The use of prebiotics is a possible example of how to try to bring to practice the GRM concept. A prebiotic action is defined as the selective stimulation of growth and/or activity(ies) of one or a limited number of microbial genus(era)/species in the gut microbiota that confer(s) health benefits to the host (Roberfroid et al., 2010).

The focus of this work will be to review the available knowledge on the effect of prebiotics on several aspects of metabolic homeostasis. In a first part, the importance of host-microbe cross-talk at the intestinal surface level is discussed. In a second part, we will discuss the microbial factors that are involved in the cross-talk between different organs of the host, and their potential management. Finally, we will give some future prospects on the use of prebiotics in an individualized approach to control metabolic disorders.

\section{Part 1. The intestinal surface as site of host-microbe crosstalk and its barrier function}

\section{Host-microbiota cross-talk at the intestinal surface along the intestinal tract}

Around $10^{14}$ microbes colonize the human gut with a coding capacity exceeding that of the host by a factor 100 (Egert et al., 2006). Throughout evolution, humans co-evolved with this abundant microbiota and an intimate interaction came to existence (Zaneveld et al., 2008). Van den Abbeele et al. (2011) recently reviewed the cross-talk at the host-microbial interface, which was crucial during this co-evolution. In addition, this cross-talk is relevant for the disturbances of the host-microbiota association, which can lead to disease states such as allergies (Bjorksten et al., 1999), inflammatory bowel diseases (Garrett et al., 2007) and obesity (Turnbaugh et al., 2006). It should be noted that the latter diseases are currently in the rise (Blaser, 2006). Key in the host-microbe cross-talk mostly is that the host continuously detects microbial signals through strategically localized host receptors (Medzhitov and Janeway, 2002). These microbial signals are referred to as microbe-associated molecular patterns (MAMPs). While fungi and viruses are often recognized through their $\beta$-glucans and 
nucleic acids, respectively, bacteria are often detected through lipopolysaccharides (LPS), peptidoglycans and teichoic acids (reviewed by Van den Abbeele et al. (2011). The host receptors that detect these MAMPs are called pathogen recognition receptors (PRRs) and include a diverse set of transmembrane (e.g. Toll-like receptors) (Takeda et al., 2003), cytosolic (e.g. NOD-like receptors) (Ting et al., 2008) and secreted receptors (e.g. collectins) (Gupta and Surolia, 2007). This allows the host to characterize the nature of the microbial signal and respond appropriately. The resulting host response includes production of antimicrobial peptides (Medzhitov and Janeway, 1997), activation of adaptive immune cells and production of resulting effector molecules including e.g. Immunoglobulin A ( $\operatorname{IgA})$ (Macpherson and Uhr, 2004). As a result of the continuous detection of microbes, host defence molecules are continuously secreted and trapped in the overlaying mucus layer, which allows the host to particularly control the composition and abundance of the mucosaassociated microbiota (Figure 1). Specific microbial characteristics such as capacity to adhere to the mucus layer, oxygen tolerance, the ability to degrade host-derived glycans further determine the unique composition of the mucosal microbiota (Van den Abbeele et al., 2011). While mucosal microbes would be crucial for priming the immune system or increasing the bioavailability of beneficial microbial metabolites at the intestinal surface, the luminal microbiota have an important metabolic function.

Given the fact that humans closely interact with their co-evolved luminal and mucosal intestinal microbiota, there is great interest in dietary interventions with e.g. prebiotic compounds that are able to modulate both the luminal and mucosal microbial composition and activity (Langlands et al., 2004; Van den Abbeele et al., 2011). In that way, prebiotics may beneficially steer the host-microbe interactions.

\section{Importance of a proper mucosal barrier and risks in case of increased permeability}

Over the last few years, the research group of Nathalie Delzenne produced several groundbreaking papers regarding the onset of obesity and its related metabolic disorders. In several studies, one investigated; the impact of a high-fat diet on the intestinal microbiota and rodent hosts (Cani et al., 2007a; Cani et al., 2008; Cani et al., 2006; Cani et al., 2007d; Cani et al., 2009b; Neyrinck et al., 2011). Rodents fed a high-fat diet suffered from impaired gut barrier function. This barrier function is crucial since it forms the basis of the strategic localization of PRRs and subsequent detection of MAMPs. This can be illustrated by the detection of lipopolysaccharides (LPS), a MAMP, trough Toll like receptor 4 (TLR-4) (Cario and Podolsky, 2000) and nucleotide-binding oligomerisation domain-1 (NOD-1) (Girardin et al., 2003) (Figure 1). TLR-4 is only in low levels expressed on the apical side of the epithelium while NOD-1 is expressed inside the cell. In this way, LPS is not detected on the apical side where it merely derives from the commensal mucosa-associated microbes but on locations where its presence may derive from potentially dangerous microbes. The increased permeability which is caused by the high-fat diet leads to LPS leakage trough the gut wall ultimately leading to increased LPS levels in the blood (endotoxemia). At that point, LPS of commensals is overly detected by the PRRs of the host resulting in inflammatory responses and symptoms of metabolic disorder (Cani et al., 2007a; Cani et al., 2008).

It has been shown that the detrimental effect corresponding to metabolic disorders can be partially reversed by reinforcing the gut barrier function. This can be obtained through modulation of the gut microbiota with (potential) prebiotic compounds such as fructans (Cani et al., 2006; Cani et al., 2007d; Cani et al., 2009b) and long-chain arabinoxylans (Neyrinck et $a l ., 2011)$. The exact nature of the microbial modulations throughout these experiments remains to be elucidated although strong indications exist that specific microbial groups may play a major role. Firstly, as bifidobacteria decreased during fat feeding (Cani et al., 2007d), 
while their abundance increased during supplementation of the (potential) prebiotic compounds (Cani et al., 2006; Cani et al., 2009b; Neyrinck et al., 2011), this genus may have an important protective role towards barrier integrity (Khailova et al., 2009). Also other studies indicate that increased bifidobacteria levels are correlated with normal weight in children (Lundell et al., 2007) and women (Collado et al., 2008), while overweight in these studies corresponded to lower bifidobacteria abundances. Improved gut barrier function has also been attributed to specific Lactobacillus spp. through protection of the epithelial tight junctions during external stress (Montalto et al., 2004; Seth et al., 2008). Besides reinforcing tight junctions between epithelial cells, restricted permeability of the gut wall may also be achieved through elevated secretion of mucin. A future focus may thus be to analyze the mucin composition of the mucus layer, which overlies the epithelium upon prebiotic treatment. This mucus layer normally consists of a double protective layer: a very dense, firmly attached and quite sterile inner mucus layer and a less dense, loosely attached, more strongly colonized outer mucus layer (Johansson et al., 2010; Schreiber, 2010). Prebiotics are typically shown to increase mucin-levels by decreasing the $\mathrm{pH}$ (Barcelo et al., 2000; Shimotoyodome et al., 2000), increasing the mechanical stimulation by increased production (Barcelo et al., 2000), especially by species residing in the mucosal environment (Van den Abbeele et al., 2011). In contrast, the type of mucin that is produced upon administration of a prebiotic compound is something which has often been neglected. This may be important as specific muc-types, such as the membrane-bound Muc17 (mouse homolog Muc3), have shown to promote epithelial barrier integrity (Resta-Lenert et al., 2011). Further, it has been shown that a mix of Lactobacillus reuteri strains is able to reach the epithelium and prevent inflammation and translocation in DSS-treated mice. It was proposed that this might be due to an increased expression of membrane-bound Muc3 (Schreiber, 2010).

In conclusion, the loss of gut barrier integrity leading to increased infiltration of microbial signals may be an important factor at the onset of obesity and its related metabolic disorders, Moreover, prebiotics may be protective by avoiding this loss of barrier integrity.

\section{Part 2. Microbial regulation of host signals involved in lipid metabolism}

Energy metabolism is regulated by several key organs including the adipose tissue, brain, liver, muscle, pancreas and the gastrointestinal tract (GIT). The diverse host parameters that are involved in these processes are listed in Table 1. This part of the review will focus on the microbial factors that are involved in the communication between the different tissues, and their potential management with prebiotics.

\section{Impact of prebiotics on gut peptides involved in fat storage}

Prebiotics may possibly have an effect on gut peptides that are involved in fat storage. The fasting induced adipose factor (FIAF), also known as angiopoietin-like protein 4 (ANGPTL4), has been thoroughly investigated as a multifunctional signal protein produced by many tissues such as the liver (Kim et al., 2010), adipose tissue (Dutton and Trayhurn, 2008), intestine (Bäckhed et al., 2004) and hypothalamus (Kim et al., 2010). Once secreted in the blood, FIAF inhibits the activity of lipoprotein lipase, an enzyme responsible for the conversion of triglycerides to monoglycerides and fatty acids from circulating lipoproteins (Mandard et al., 2006; Yoshida et al., 2002). As a consequence, these triglycerides cannot be stored in the fat tissue, resulting in a lower body weight (Bäckhed et al., 2004). 
A particular feature of the intestinal FIAF gene is that its expression is strongly regulated by the presence of an intestinal microbial community (Bäckhed et al., 2004; Fleissner et al., microbial community compared to germ-free mice. Further, conventionalization of these germ-free animals with intestinal bacteria significantly decreased FIAF levels, resulting in an enhanced fat storage and weight gain (Bäckhed et al., 2004). Moreover, elevated FIAF levels may protect germ-free mice against certain types of high-fat diet-induced obesity through induction of the peroxisome proliferator-activated receptor- $\gamma$ coactivator-1 $\alpha$ (Pgc-1 $\alpha)$, thereby regulating genes involved in energy metabolism (Bäckhed et al., 2007; Fleissner et al., 2010). Fleissner et al. (2010) reported that, despite the intestinal FIAF repression in conventionalized mice, their plasma FIAF levels were not decreased as compared to germfree mice. In contrast, in conventionalized mice, a higher concentration of cleaved FIAF was observed whereas the native FIAF concentration was unchanged. These results suggest that the microbial community increases (cleaved) FIAF in sites of the body other than the intestine. Therefore, the impact of the microbial community on FIAF regulated processes should be further explored, not only in the intestine, but also in other parts of the human body. To the best of our knowledge, only one substrate with impact on FIAF expression was reported. In obese mice fed a high fat diet, it was observed that chitosan from mushrooms significantly decreased FIAF expression in visceral adipose tissue (Neyrinck et al., 2009). It was however not investigated whether this was due to shifts in either microbial fermentation products or in composition of the microbial community.

Grootaert et al. (2011) showed that SCFAs such as butyrate and propionate, but not acetate, stimulate FIAF transcription in several colorectal and hepatic cancer cell lines. When investigating the effect of specific intestinal monocultures, differential effects on FIAF expression were identified. An in vivo mouse study from Bäckhed et al. (2007) demonstrated that FIAF production was more repressed when inoculating germ-free mice with a combination of Bacteroides thetaiotaomicron and Methanobrevibacter smithii, than with each of them separately. Incubation of HCT-116 cells with E. coli resulted in decreased FIAF secretion (Grootaert et al., 2011). In contrast, in vitro incubations of intestinal HT-29 and Caco-2 cells with Enterococcus faecalis increased FIAF production after a few hours (Are et al., 2008; Grootaert et al., 2011). Similarly, it was shown that Lactobacillus paracasei ssp paracasei F19, Lactobacillus rhamnosus GG and Bifidobacterium lactis BB12, and not Bacteroides thetaiotaomicron, were able to stimulate FIAF expression in several colonic cell lines including HCT-116, HT-29, LoVo and SW-480 cells (Aronsson et al., 2010). In the case of Lactobacillus F19, the FIAF stimulatory effect was attributed to a secreted microbial factor, which was however not identified in the study. In addition, conventionalization of mice with Lactobacillus F19 increased native FIAF levels in blood plasma, and resulted in decreased fat storage and increased blood VLDL levels.

Summarized, although FIAF is an interesting molecule to focus on for prebiotic treatment, its functionality largely depends on the site of production, isoform appearance and final target organs. Until now, the most dominating effect of microbial FIAF modulation is not identified yet and needs further investigation with relevant models.

\section{Prebiotics that alter energy intake through satiety signals}

Prebiotics may also be used to decrease appetite by modulation of specific hormones involved in appetite and satiety. Leptin is a hormone mainly produced by adipose tissues and inhibits food intake. Prebiotic substrates such as chitosan decrease the production of leptin in adipocytes in high fat diet-induced obese mice (Neyrinck et al., 2009), although the exact mode-of-action is not known. In addition, leptin was also decreased in rats weaned with 
inulin-containing high fiber diets (Maurer et al., 2009). Xiong et al. (2004) demonstrated that SCFA belonging to $\mathrm{C} 2-\mathrm{C} 6$ fatty acids stimulate leptin in murine adipocyte cell lines and primary adipocyte cell culture. In case of propionate, significantly increased leptin production was attributed to increased GPR41 activation. Leptin stimulation through G-coupled protein receptors was also shown in human adipose tissue (Lahham et al., 2008).

Glucagon-like peptide 1 (GLP-1) and peptide YY (PYY) are satiety stimulating hormones, released in response to nutrient ingestion by L-cells in mainly ileum and colon. GLP-1 promotes insulin secretion and pancreatic $\beta$-cell proliferation and controls glycogen synthesis in muscle cells (Delzenne et al., 2007), whereas PYY slows down gastric emptying. In contrast, ghrelin stimulates appetite and is mainly produced by P/D1 cells in the stomach and $\varepsilon$-cells of the pancreas (Inui et al., 2004).

Non-digestible carbohydrates, such as oligofructose (Cani et al., 2007b; Maurer et al., 2009; Piche et al., 2003), lactitol (Gee and Johnson, 2005) and resistant starch (Zhou et al., 2008) are effective to induce satiety by modulating the production of the gut peptides GLP-1, PYY and ghrelin through a mechanism that also involves modulation of the intestinal microbial community (Cani et al., 2007b). For instance, rats fed a oligofructose-enriched diet showed a significantly increased GLP-1 and decreased ghrelin production, and doubled the number of GLP-1-expressing cells in the proximal colon (Cani et al., 2004; Cani et al., 2007c). In addition, also human studies showed higher plasma GLP-1, PYY and/or ghrelin levels after intake of oligofructose (Cani et al., 2009a; Parnell and Reimer, 2009; Piche et al., 2003), which may explain the increased satiety feeling and decreased energy intake behaviour of the subjects. Finally, lactitol mainly increased PYY production both in rats and humans (Gee and Johnson, 2005), whereas resistant starch significantly increased both PYY and GLP-1 production (Zhou et al., 2008). The bacterial regulation of gut peptides is mediated by SCFA produced from these indigestible substrates. Physiological concentrations of acetate, propionate and butyrate, but also a $\mathrm{pH}$ decrease from 7.5 to 6 , significantly increased proglucagon and PYY in the entero-endocrine colon cell line STC-1 (Zhou et al., 2008). In addition, the presence of glucose in the intestine also enhances the GLP-1 production in the Lcells (Egan and Margolskee, 2008). These mechanisms may explain why gut peptide modulation is only observed with highly fermentable fibers (Massimino et al., 1998).

Recently, also FIAF was identified as a potential signal protein with effect on hypothalamic control of appetite. Bacteria by means of LPS are able to induce a low-grade inflammation, as already discussed (Cani et al., 2007a). Brown et al. (2009) showed that when mice were treated with LPS, body weight was significantly decreased and increased levels of FIAF were observed in the hypothalamic, pituitary, cortical and adipose tissues. Similar effects on FIAF levels were observed when N-1 neuronal and 3T3-L1 adipocyte cells were treated with LPS (Brown et al., 2009). Therefore, FIAF is considered as one of the mediators of hypothalamic control of appetite and energy metabolism through LPS. In fact, LPS-induced endotoxemia was also associated to an anorectic response via hypothalamic-dependent mechanisms (Huang et al., 1999; Rummel et al., 2008). Yet, it is not desirable to steer this FIAF response by addition of LPS to the host, as LPS stimulates inflammatory responses in other tissues.

In summary, we conclude that the influence of microbiota on satiety hormones is a promising issue for prebiotic treatment, especially for substrates that enhance SCFA production. Indeed, a large part of the SCFAs are transported into the blood stream, thereby targeting several tissues, such as the adipose tissue, which may be induced to produce hormones involved in appetite and satiety.

\section{Prebiotic modulation of cholesterol and lipid metabolism}


Several pro- and prebiotics may have a possible effect on serum cholesterol and lipid levels, thereby not only affecting fat storage, but also the development of cardiovascular diseases (reviewed by Ooi and Liong (2010) and Williams (1997)). Several mechanisms have been proposed, including enzymatic deconjugation of bile acids (Bongaerts et al., 2000), assimilation of cholesterol (reviewed by St-Onge et al. (2000)), co-precipitation of cholesterol with deconjugated bile, cholesterol binding to bacterial cell walls, incorporation of cholesterol into microbial cell membranes, conversion of cholesterol into coprostanol and production of short-chain fatty acids upon fermentation (reviewed by Ooi and Liong (2010)). Examples of probiotic bacteria influencing cholesterol and lipid metabolism are Lactococcus lactis (Nakajima et al., 1992), Streptococcus thermophilus (Pulusani and Rao, 1983; Richelsen et al., 1996), Lactobacillus acidophilus (Gilliland et al., 1985), E. faecium (Richelsen et al., 1996), Bifidobacterium bifidum (Beena and Prasad, 1997; Mohan et al., 1996) and B. longum (Xiao et al., 2003).

Several human and rodent in vivo studies also mention the cholesterol and lipid lowering effects of oligofructose (de Luis et al., 2010; Delzenne et al., 1993; Fiordaliso et al., 1995; Trautwein et al., 1998; Williams and Jackson, 2002), xylo-oligosaccharides (Hsu et al., 2004), chito-oligosaccharides ( $\mathrm{Li}$ et al., 2007), soybean oligosaccharides (Chen et al., 2010) and resistant starch (Cheng and Lai, 2000; Venter et al., 1990). These effects may be linked to the production of propionate, which inhibits hepatic cholesterol synthesis from acetate (Berggren et al., 1996; Lin et al., 1995; Todesco et al., 1991). Yet, the concentration of propionate that is needed to induce the cholesterol and lipid lowering effect is 10 to 100 fold higher for human than for rat hepatocytes (Lin et al., 1995).

Hepatic lipogenesis is not only regulated by short chain fatty acids, but also by serum glucose and insulin levels (Towle, 2001). Enhanced sugar uptake has been observed in presence of gut bacteria compared to germ-free conditions, which can be explained by several mechanisms. First of all, the presence of an intestinal microbial community leads towards an increase in the amount of capillaries that underlie the small intestinal epithelium (Hooper et al., 2002). Secondly, host monosaccharide transporters are induced by the polysaccharide-processing activity of the microbiota, as was demonstrated by studies with germ-free mice colonized with B. thetaiotaomicron (Hooper et al., 2001). The monomers generated from indigestible polysaccharides are delivered as substrates for lipid production in the liver. Besides, they may also activate the lipogenic enzymes in the liver by ChREBP- and SREBP-1- mediated mechanisms (Bäckhed et al., 2004). Hence, the polysaccharide-degrading potential of an intestinal microbial community may be an important determinant for hepatic lipid production. In obese $o b / o b$ mice, the intestinal microbial community is enriched for genes that are able to harvest calories from complex plant-derived polysaccharides compared to lean mice. These genes encode for enzymes involved in sugar degradation, sugar transport and acetate and butyrate production (Turnbaugh et al., 2006).

We conclude that the potential influence of intestinal microbiota and prebiotics on lipid and cholesterol production in the host is a complicated process which involves several nutrients, target organs and signalling pathways. More investigation is warranted to identify the dominating mechanism by which prebiotic modulation of the intestinal microbial community may contribute to lipid and cholesterol lowering effects.

\section{Part 3: Prebiotic modulation of glucose and insulin metabolism}

As mentioned before, intestinal bacteria can impact food intake and lipid metabolism, but may also be involved in carbohydrate maintenance and disturbances thereof, such as insulin resistance. Insulin resistance is the fundamental defect in type 2 diabetes, a disease that afflicts 6\% of adult Americans, up from 3\% in the early 1970s (Taubes, 2009). A role of 
dietary fibers in general and prebiotics in particular has been shown in regulating glucose maintenance in numerous studies and will therefore also be used in this part to illustrate the role of intestinal bacteria.

Indeed, consumption of whole grains dietary fibers has been shown to improve blood glucose and insulin responses (reviewed by Gemen et al. (2011)). It is now believed that the underlying mechanism is of a multifactorial nature with different activity profiles throughout the gastrointestinal tract (Figure 2). Firstly, inclusion of dietary fiber in dietary products may replace part of the available carbohydrates in the food product, leading to lower glycemic response. For instance, resistant starch lowers the glycemic index, by being indigestible in the upper intestine, as opposed to digestible starch. The resistance to digestion of resistant starch is mainly attributed to particular physical structures, such as the amylose / amylopectin ratio. A higher ratio leads to a more branched polymer structure, which is less susceptible to enzymatic digestion in the small intestine (Brouns et al., 2002; Fassler et al., 2006; Storey et al., 2007; Venter et al., 1990). Secondly, depending on their structure, dietary fibers such as arabinoxylans and beta-glucans, form a viscous solution in the stomach, thereby delaying gastric emptying and physically trapping nutrients, such as glucose and thereby reducing their absorption. In addition, the passage of digestive enzymes through the viscous food bolus is limited, which reduces the hydrolysis by digestive enzymes (Mohlig et al., 2005; Regand et al., 2009; Wood et al., 2000). The combination of these processes will again lower the glycemic response. Reduced serum glucose concentrations decrease the amount of insulin needed to clear the glucose load. Upon repeated consumption of such fiber, the reduced ambient insulin concentrations may result in an up-regulation of cell surface insulin receptors, thereby increasing insulin sensitivity (Song et al., 2000).

As mentioned before, changes in the intestinal bacterial community are involved in obesity, but also in insulin resistance. Interesting work has recently been published on the use of mice genetically deficient in Toll-like receptor 5 (TLR5). These mice spontaneously develop symptoms of the metabolic syndrome, among which insulin resistance (Vijay-Kumar et al., 2010). Transfer of the intestinal microbiota of these mice into germ-free wild-type mice allowed transferring the metabolic phenotype into the wild-type mice, including insulin resistance. As this shows that specific microbial community composition may be implicated in insulin resistance, alterations of the community through dietary interventions may also affect glucose and insulin metabolism. A third mode of action of dietary fibers may therefore be related to the modulation of the intestinal microbiota.

Dietary fibers are typically non-digestible and therefore reach the colon, where they can be metabolized into SCFA by the intestinal bacteria. There is evidence that hepatocytes may, when exposed to an increase in short-chain fatty acids, increase glucose oxidation, decrease fatty acid release, and increase insulin clearance - an environment conductive to enhanced insulin sensitivity (Frayn et al., 1996; Thorburn et al., 1993; Venter et al., 1990). This would be related with specific interactions with G-protein-coupled receptors GPR41 and GPR43 (Delzenne and Cani, 2011; Dewulf et al., 2010). Whereas acetate is typically considered to act as substrate for lipogenesis in the liver, propionate would inhibit de novo lipogenesis and gluconeogenesis from lactate, decrease inflammation and improve insulin sensitivity (AlLahham et al., 2010; Berggren et al., 1996; Lin et al., 1995). Finally, butyrate has also been linked with improved insulin sensitivity (Gao et al., 2009).

As described in the section on the role of the intestinal barrier and low-grade inflammation in obesity and metabolic disorders, specific changes induced in microbial community composition upon (prebiotic) fiber intake may also be involved in improvements of glucose maintenance, through altered host-bacteria interactions, involving improvement of gut barrier function and reduction of LPS leakage (Cani and Delzenne, 2009; Neyrinck et al., 2010; 
Neyrinck et al., 2011). In addition, dietary fibers such as beta-glucans, may directly interact with the mucosal immune system and influence insulin sensitivity through immunemodulation (King et al., 2007; Vos et al., 2007).

Delzenne and Cani (2011) recently summarized the current evidence on the relation between specific microbial community composition and diabetes. Changes in community composition seem to involve reduced presence of Firmicutes as opposed to Bacteroidetes (Larsen et al., 2010). Other researchers showed lower representation of the genus Bifidobacterium and Bacteroides vulgatus (Wu et al., 2010) or the abundance of Faecalibacterium prausnitzii (Furet et al., 2010) in microbiota from diabetic individuals and a lower presence of microbiota-related metabolites in the blood and urine of diabetic individuals (Lucio et al., 2010; Zhao et al., 2010). The interaction between dietary fibers, intestinal microbiota and gut peptide hormones has been described extensively in relation to weight management and lipid metabolism (Cani et al., 2005; Delzenne and Cani, 2011; Delzenne et al., 2007). Interaction of these peptide hormones with glucose metabolism and insulin sensitivity was also shown in numerous animal studies (Delzenne and Cani, 2010) For instance, dietary fiber such as oligofructose can increase the number of endocrine L-cells in the proximal colon of rats (Cani et al., 2007c) and increase the production of GLP-1 and GLP-2, the former being involved in the regulation of insulin sensitivity (Maurer and Reimer, 2011) and the latter in barrier function control (Cani et al., 2009b). Another example is the potential role of adiponectin (Weickert and Pfeiffer, 2008). In a cross-sectional analysis, high intakes of cereal dietary fiber were positively associated with plasma adiponectin after adjusting for lifestyle factors and dietary glycemic load (Qi et al., 2005). Adiponectin may act as a peripheral starvation signal promoting the storage of triglycerides preferentially in adipose tissue (Kim et al., 2007). As a consequence, reduced triglyceride accumulation in the liver and in the skeletal muscle might convey improved systemic insulin sensitivity (Weickert and Pfeiffer, 2006).

Summarized, the positive effects of (prebiotic) dietary fibers on postprandial glucose and insulin response are becoming more and more clear. Recently, Gemen et al. (2011) provided a clear overview of the existing scientific literature, in which 39 publications were referred to. Although further research is needed to differentiate the variety of existing fiber sources in their efficacy and specific mode of action, the basic principles of the underlying mechanisms and the intriguing role of the gut microbiota become unravelled.

\section{Future perspectives}

The studies described in this review - although they have been conducted on animals - suggest that a successful prebiotic intervention with respect to obesity and its related metabolic disorders could be possible (Cani et al., 2006; Cani et al., 2007d; Cani et al., 2009b; Neyrinck et al., 2011). However, new metagenomic technologies have also pointed out that the interindividual variability of our holobiont is a key factor for the success of a given strategy. For instance, Walker et al. (2011) recently showed a strong variation in terms of microbial modulation among human subjects in response to prebiotic supplementation. As a consequence, the management of the intestinal microbiota with the aim of improving human health will optimally require a prior characterization of the microbiota, i.e. the concept of personalized health-care. In this respect, several options may be available. When the necessary genes/species/strains are present, one may target them through specific prebiotics. If not present, the so-called synbiotic approach could be a valuable solution: addition of specific bacteria with a metabolic capability of interest (e.g. probiotics but also microbes beyond the current definition such as butyrate producing species - Eubacterium rectale, Faecalibacterium prausnitsii, Anaerostipes caccae, Roseburia intestinalis). A final option 
430 could be the transfer of entire communities (or part of the microbial population) through 431 faecal transplantation (Khoruts et al., 2010), as an extension of the concept of synbiotics. This 432 implies that studies demonstrating the beneficial effect of prebiotics are useful but need a 433 better characterization of the exact modulation of the intestinal microbiota (both luminal and 434 mucosal microbiota) in order to mechanistically explain the beneficial host effect. As an 435 alternative to the individual specific approach, it may be possible that individuals may be 436 grouped and subsequently treated with specific prebiotics based on an enterotype-like 437 classification as proposed by (Arumugam et al., 2011). 


\section{References}

Al-Lahham, S.H., Peppelenbosch, M.P., Roelofsen, H., Vonk, R.J. and Venema, K., 2010. Biological effects of propionic acid in humans; metabolism, potential applications and underlying mechanisms. Biochimica Et Biophysica Acta-Molecular and Cell Biology of Lipids 1801: 1175-1183.

Are, A., Aronsson, L., Wang, S., Greicius, G., Lee, Y.K., Gustafsson, J.-Ã., Pettersson, S. and Arulampalam, V., 2008. Enterococcus faecalis from newborn babies regulate endogenous PPAR $\gamma$ activity and IL-10 levels in colonic epithelial cells. Proceedings of the National Academy of Sciences of the United States of America 105: 1943-1948.

Aronsson, L., Huang, Y., Parini, P., Korach-André, M., Hakansson, J., Gustafsson, J.A., Pettersson, S., Arulampalam, V. and Rafter, J.J., 2010. Decreased fat storage by Lactobacillus paracasei is associated with increased levels of angiopoietin-like 4 protein (ANGPTL4). PLoS One 5: e13078.

Arumugam, M., Raes, J., Pelletier, E., Le Paslier, D., Yamada, T., Mende, D.R., Fernandes, G.R., Tap, J., Bruls, T., Batto, J.M., Bertalan, M., Borruel, N., Casellas, F., Fernandez, L., Gautier, L., Hansen, T., Hattori, M., Hayashi, T., Kleerebezem, M., Kurokawa, K., Leclerc, M., Levenez, F., Manichanh, C., Nielsen, H.B., Nielsen, T., Pons, N., Poulain, J., Qin, J., Sicheritz-Ponten, T., Tims, S., Torrents, D., Ugarte, E., Zoetendal, E.G., Wang, J., Guarner, F., Pedersen, O., de Vos, W.M., Brunak, S., Dore, J., Consortium, M., Weissenbach, J., Ehrlich, S.D., Bork, P., Antolin, M., Artiguenave, F., Blottiere, H.M., Almeida, M., Brechot, C., Cara, C., Chervaux, C., Cultrone, A., Delorme, C., Denariaz, G., Dervyn, R., Foerstner, K.U., Friss, C., van de Guchte, M., Guedon, E., Haimet, F., Huber, W., van Hylckama-Vlieg, J., Jamet, A., Juste, C., Kaci, G., Knol, J., Lakhdari, O., Layec, S., Le Roux, K., Maguin, E., Merieux, A., Melo Minardi, R., M'Rini, C., Muller, J., Oozeer, R., Parkhill, J., Renault, P., Rescigno, M., Sanchez, N., Sunagawa, S., Torrejon, A., Turner, K., Vandemeulebrouck, G., Varela, E., Winogradsky, Y. and Zeller, G., 2011. Enterotypes of the human gut microbiome. Nature 473: 174-180.

Bäckhed, F., Ding, H., Wang, T., Hooper, L.V., Koh, G.Y., Nagy, A., Semenkovich, C.F. and Gordon, J.I., 2004. The gut microbiota as an environmental factor that regulates fat storage. Proceedings of the National Academy of Sciences of the United States of America 101: 15718-15723.

Bäckhed, F., Manchester, J.K., Semenkovich, C.F. and Gordon, J.I., 2007. Mechanisms underlying the resistance to diet-induced obesity in germ-free mice. Proceedings of the National Academy of Sciences of the United States of America 104: 979-984.

Barcelo, A., Claustre, J., Moro, F., Chayvialle, J.A., Cuber, J.C. and Plaisancie, P., 2000. Mucin secretion is modulated by luminal factors in the isolated vascularly perfused rat colon. Gut 46: 218-224.

Beena, A. and Prasad, V., 1997. Effect of yogurt and bifidus yogurt fortified with skim milk powder, condensed whey and lactose-hydrolysed condensed whey on serum cholesterol and triacylglycerol levels in rats. Journal of Dairy Research 64: 453-457.

Berggren, A., Nyman, E.M.G.L., Lundquist, I. and Björck, I.M.E., 1996. Influence of orally and rectally administered propionate on cholesterol and glucose metabolism in obese rats. British Journal of Nutrition 76: 287-294.

Bjorksten, B., Naaber, P., Sepp, E. and Mikelsaar, M., 1999. The intestinal microflora in allergic Estonian and Swedish 2-year-old children. Clinical and Experimental Allergy: Journal of the British Society for Allergy and Clinical Immunology 29: 342-346.

Blaser, M.J., 2006. Who are we? Indigenous microbes and the ecology of human diseases. European Molecular Biology Organization Reports 7: 956-960. 
Bongaerts, G.P., Severijnen, R.S., Tangerman, A., Verrips, A. and Tolboom, J.J., 2000. Bile acid deconjugation by Lactobacilli and its effects in patients with a short small bowel. Journal of Gastroenterology 35: 801-804. Brouns, F., Kettlitz, B. and Arrigini, E., 2002. Resistant starch and "the butyrate revolution". Trends in Food Science and Technology 13: 251-261.

Brown, R., Imran, S.A. and Wilkinson, M., 2009. Lipopolysaccharide (LPS) stimulates adipokine and socs3 gene expression in mouse brain and pituitary gland in vivo, and in $\mathrm{N}-1$ hypothalamic neurons in vitro. Journal of Neuroimmunology 209: 96-103.

Burcelin, R., Luche, E., Serino, M. and Amar, J., 2009. The gut microbiota ecology: a new opportunity for the treatment of metabolic diseases? Frontiers in Bioscience 14: 5107-5117.

Caesar, R., Fak, F. and Backhed, F., 2010. Effects of gut microbiota on obesity and atherosclerosis via modulation of inflammation and lipid metabolism. Journal of Internal Medicine 268: 320-328.

Cani, P.D., Amar, J., Iglesias, M.A., Poggi, M., Knauf, C., Bastelica, D., Neyrinck, A.M., Fava, F., Tuohy, K.M., Chabo, C., Waget, A., Delmee, E., Cousin, B., Sulpice, T., Chamontin, B., Ferrieres, J., Tanti, J.F., Gibson, G.R., Casteilla, L., Delzenne, N.M., Alessi, M.C. and Burcelin, R., 2007a. Metabolic endotoxemia initiates obesity and insulin resistance. Diabetes 56: 1761-1772.

Cani, P.D., Bibiloni, R., Knauf, C., Neyrinck, A.M., Delzenne, N.M. and Burcelin, R., 2008. Changes in gut microbiota control metabolic endotoxemia-induced inflammation in high-fat diet-induced obesity and diabetes in mice. Diabetes 57: 1470-1481.

Cani, P.D., Daubioul, C.A., Reusens, B., Remacle, C., Catillon, G. and Delzenne, N.M., 2005. Involvement of endogenous glucagon-like peptide-1(7-36) amide on glycaemia-lowering effect of oligofructose in streptozotocin-treated rats. Journal of Endocrinology 185: 457-465. Cani, P.D. and Delzenne, N.M., 2007. Gut microflora as a target for energy and metabolic homeostasis. Current Opinion in Clinical Nutrition and Medical Care 10: 729-734.

Cani, P.D. and Delzenne, N.M., 2009. Interplay between obesity and associated metabolic disorders: new insights into the gut microbiota. Current Opinion in Pharmacology 9: 737-743. Cani, P.D., Dewever, C. and Delzenne, N.M., 2004. Inulin-type fructans modulate gastrointestinal peptides involved in appetite regulation (glucagon-like peptide-1 and ghrelin) in rats. British Journal of Nutrition 92: 521-526.

Cani, P.D., Holst, J.J., Drucker, D.J., Delzenne, N.M., Thorens, B., Burcelin, R. and Knauf, C., 2007b. GLUT2 and the incretin receptors are involved in glucose-induced incretin secretion. Molecular and Cellular Endocrinology 276: 18-23.

Cani, P.D., Hoste, S., Guiot, Y. and Delzenne, N.M., 2007c. Dietary non-digestible carbohydrates promote L-cell differentiation in the proximal colon of rats. British Journal of Nutrition 98: 32-37.

Cani, P.D., Knauf, C., Iglesias, M.A., Drucker, D.J., Delzenne, N.M. and Burcelin, R., 2006. Improvement of glucose tolerance and hepatic insulin sensitivity by oligofructose requires a functional glucagon-like peptide 1 receptor. Diabetes 55: 1484-1490.

Cani, P.D., Lecourt, E., Dewulf, E.M., Sohet, F.M., Pachikian, B.D., Naslain, D., De Backer, F., Neyrinck, A.M. and Delzenne, N.M., 2009a. Gut microbiota fermentation of prebiotics increases satietogenic and incretin gut peptide production with consequences for appetite sensation and glucose response after a meal. American Journal of Clinical Nutrition 90: 12361243.

Cani, P.D., Neyrinck, A.M., Fava, F., Knauf, C., Burcelin, R.G., Tuohy, K.M., Gibson, G.R. and Delzenne, N.M., 2007d. Selective increases of bifidobacteria in gut microflora improve high-fat-diet-induced diabetes in mice through a mechanism associated with endotoxaemia. Diabetologia 50: 2374-2383. 
Cani, P.D., Possemiers, S., Van de Wiele, T., Guiot, Y., Everard, A., Rottier, O., Geurts, L., Naslain, D., Neyrinck, A., Lambert, D.M., Muccioli, G.G. and Delzenne, N.M., 2009b.

540 Changes in gut microbiota control inflammation in obese mice through a mechanism 541 involving GLP-2-driven improvement of gut permeability. Gut 58: 1091-1103.

542 Cario, E. and Podolsky, D.K., 2000. Differential alteration in intestinal epithelial cell expression of toll-like receptor 3 (TLR3) and TLR4 in inflammatory bowel disease. Infection and Immunity 68: 7010-7017.

Chen, H., Liu, L.-J., Zhu, J.-J., Xu, B. and Li, R., 2010. Effect of soybean oligosaccharides on blood lipid, glucose levels and antioxidant enzymes activity in high fat rats. Food Chemistry 119: 1633-1636.

Cheng, H.-H. and Lai, M.-H., 2000. Fermentation of resistant rice starch produces propionate reducing serum and hepatic cholesterol in rats. Journal of Nutrition 130: 1991-1995.

Collado, M.C., Isolauri, E., Laitinen, K. and Salminen, S., 2008. Distinct composition of gut microbiota during pregnancy in overweight and normal-weight women. American Journal of Clinical Nutrition 88: 894-899.

de Luis, D.A., de la Fuente, B., Izaola, O., Conde, R., Gutierrez, S., Morillo, M. and Teba Torres, C., 2010. Randomized clinical trial with a inulin enriched cookie on risk cardiovascular factor in obese patients. Nutrición Hospitalaria 25: 53-59.

Delzenne, N.M. and Cani, P.D., 2010. Nutritional modulation of gut microbiota in the context of obesity and insulin resistance: potential interest of prebiotics. International Dairy Journal 20: 277-280.

Delzenne, N.M. and Cani, P.D., 2011. Gut microbiota and the pathogenesis of insulin resistance. Current Diabetes Reports 11: 154-159.

Delzenne, N.M., Cani, P.D. and Neyrinck, A.M., 2007. Modulation of glucagon-like peptide 1 and energy metabolism by inulin and oligofructose: experimental data. Journal of Nutrition 137: S2547-S2551.

Delzenne, N.M., Kok, N., Fiordaliso, M., Deboyser, D., Goethals, F. and Roberfroid, M.B., 1993. Dietary fructo-oligosaccharides modifies lipid metabolism in rats. American Journal of Clinical Nutrition 57: 8205.

Dewulf, E., Neyrinck, A.M., Possemiers, S., Deldicque, L., Bindels, L.B., Pachikian, B.D., Sohet, F.M., Francaux, M., Cani, P.D. and Delzenne, N.M., 2010. Involvement of receptors for short chain carboxylic acids and GPR41 GPR43-in the control of radipogenesis by prebiotics, modulators of selective intestinal microbiota. Diabetes \& Metabolism 36: A35A35.

Dutton, S. and Trayhurn, P., 2008. Regulation of angiopoietin-like protein 4/fasting-induced adipose factor (ANGPTL4/FIAF) expression in mouse white adipose tissue and 3T3-L1 adipocytes. British Journal of Nutrition 100: 18-26.

Egan, J.M. and Margolskee, R.F., 2008. Taste cells of the gut and gastrointestinal chemosensation. Molecular Interventions 8: 78-81.

Egert, M., de Graaf, A.A., Smidt, H., de Vos, W.M. and Venema, K., 2006. Beyond diversity: functional microbiomics of the human colon. Trends in Microbiology 14: 86-91.

Fassler, C., Arrigoni, E., Venema, K., Brouns, F. and Amado, R., 2006. In vitro fermentability of differently digested resistant starch preparations. Molecular Nutrition and Food Research 50: $1220-1228$.

Fiordaliso, M.F., Kok, N., Desager, J.P., Goethals, F., Deboyser, D., Roberfroid, M.B. and Delzenne, N.M., 1995. Dietary oligofructose lowers triacylglycerols, phospholipids and cholesterol in serum and very low density lipoproteins of rats. Lipids 30: 163-167.

Fleissner, C.K., Huebel, N., Abd El-Bary, M.M., Loh, G., Klaus, S. and Blaut, M., 2010. Absence of intestinal microbiota does not protect mice from diet-induced obesity. British Journal of Nutrition 104: 919-929. 
Frayn, K.N., Williams, C.M. and Arner, P., 1996. Are increased plasma nonesterified fatty acid concentrations a risk marker for coronary heart disease and other chronic diseases? 590 Clinical Science 90: 243-253.

591 Furet, J.P., Kong, L.C., Tap, J., Poitou, C., Basdevant, A., Bouillot, J.L., Mariat, D., Corthier, G., Dore, J., Henegar, C., Rizkalla, S. and Clement, K., 2010. Differential adaptation of grade inflammation markers. Diabetes 59: 3049-3057.

Gao, Z.G., Yin, J., Zhang, J., Ward, R.E., Martin, R.J., Lefevre, M., Cefalu, W.T. and Ye, J.P., 2009. Butyrate improves insulin sensitivity and increases energy expenditure in mice. Diabetes 58: 1509-1517.

Garrett, W.S., Lord, G.M., Punit, S., Lugo-Villarino, G., Mazmanian, S.K., Ito, S., Glickman, J.N. and Glimcher, L.H., 2007. Communicable ulcerative colitis induced by T-bet deficiency in the innate immune system. Cell 131: 33-45.

Gee, J.M. and Johnson, I.T., 2005. Dietary lactitol fermentation increases circulating peptide YY and glucagon-like peptide-1 in rats and humans. Nutrition 21: 1036-1043.

Gemen, R., de Vries, J.F. and Slavin, J.L., 2011. Relationship between molecular structure of cereal dietary fiber and health effects: focus on glucose/insulin response and gut health. Nutrition Reviews 69: 22-33.

Gilliland, S.E., Nelson, C.R. and Maxwell, C., 1985. Assimilation of cholesterol by Lactobacillus acidophilus. Applied Environmental Microbiology 49: 377-381.

Girardin, S.E., Boneca, I.G., Carneiro, L.A., Antignac, A., Jehanno, M., Viala, J., Tedin, K., Taha, M.K., Labigne, A., Zahringer, U., Coyle, A.J., DiStefano, P.S., Bertin, J., Sansonetti, P.J. and Philpott, D.J., 2003. Nod1 detects a unique muropeptide from gram-negative bacterial peptidoglycan. Science 300: 1584-1587.

Grootaert, C., Van de Wiele, T., Van Roosbroeck, I., Possemiers, S., Vercoutter-Edouart, A.S., Verstraete, W., Bracke, M. and Vanhoecke, B., 2011. Bacterial monocultures, propionate, butyrate and $\mathrm{H}_{2} \mathrm{O}_{2}$ modulate the expression, secretion and structure of the fasting induced adipose factor in gut epithelial cell lines. Environmental Microbiology 13: 1778-1789.

Gupta, G. and Surolia, A., 2007. Collectins: sentinels of innate immunity. Bioessays 29: 452464.

Hooper, L.V., Midtveld, T. and Gordon, J.I., 2002. How host-microbial interactions shape the nutrient environment of the mammalian intestine. Annual Review of Nutrition 22: 283-307.

Hooper, L.V., Wong, M.H., Thelin, A., Hansson, L., Falk, P.G. and Gordon, J.I., 2001. Molecular analysis of commensal host-microbial relationships in the intestine. Science 291: 881-884.

Hsu, C.K., Liao, J.W., Chung, Y.C., Hsieh, C.P. and Chan, Y.C., 2004. Xylooligosaccharides and fructooligosaccharides affect the intestinal microbiota and precancerous colonic lesion development in rats. Journal of Nutrition 134: 1523-1528.

Huang, Q.-H., Hruby, V.J. and Tatro, J.B., 1999. Role of central melanocortins in endotoxininduced anorexia. Americal Journal of Physiology - Regulatory, Integrative and Comparative Physiology 276: 864-871.

Inui, A., Asakawa, A., Bowers, C.Y., Mantovani, G., Laviano, A., Meguid, M.M. and Fujimiya, M., 2004. Ghrelin, appetite, and gastric motility: the emerging role of the stomach as an endocrine organ. Faseb Journal 18: 439-456.

Johansson, M.E., Gustafsson, J.K., Sjoberg, K.E., Petersson, J., Holm, L., Sjovall, H. and Hansson, G.C., 2010. Bacteria penetrate the inner mucus layer before inflammation in the dextran sulfate colitis model. PLoS One 5: e12238.

Khailova, L., Dvorak, K., Arganbright, K.M., Halpern, M.D., Kinouchi, T., Yajima, M. and Dvorak, B., 2009. Bifidobacterium bifidum improves intestinal integrity in a rat model of 
necrotizing enterocolitis. American Journal of Physiology - Gastrointestinal and Liver 638 Physiology 297: G940-G949.

639 Khoruts, A., Dicksved, J., Jansson, J.K. and Sadowsky, M.J., 2010. Changes in the composition of the human fecal microbiome after bacteriotherapy for recurrent Clostridium difficile-associated diarrhea. Journal of Clinical Gastroenterology 44: 354-360.

Kim, H.K., Youn, B.S., Shin, M.S., Namkoong, C., Park, K.H., Baik, J.H., Kim, J.B., Park, J.Y., Lee, K.U., Kim, Y.B. and Kim, M.S., 2010. Hypothalamic ANGPTL4/Fiaf is a novel regulator of food intake and body weight. Diabetes 59: 2772-2780.

Kim, J.Y., De Wall, E.V., Laplante, M., Azzara, A., Trujillo, M.E., Hofmann, S.M., Schraw, T., Durand, J.L., Li, H., Li, G., Jelicks, L.A., Mehler, M.F., Hui, D.Y., Deshaies, Y., Shulman, G.I., Schwartz, G.J. and Scherer, P.E., 2007. Obesity-associated improvements in metabolic profile through expansion of adipose tissue. Journal of Clinical Investigation 117: 2621-2637.

King, D.E., Egan, B.M., Woolson, R.F., Mainous, A.G., Al-Solaiman, Y. and Jesri, A., 2007. Effect of a high-fiber diet vs a fiber-supplemented diet on C-reactive protein level. Archives of Internal Medicine 167: 502-506.

Lahham, S.H., Weening, D., Rezaee, F., Roelofsen, H. and Venema, K., 2008. Propionic acid stimulates leptin production in human adipose tissue through G-protein coupled receptor(s). 10th annual Gut Day: University Medical Centre Utrecht and Gut Flora Foundation, The Netherlands.

Langlands, S.J., Hopkins, M.J., Coleman, N. and Cummings, J.H., 2004. Prebiotic carbohydrates modify the mucosa associated microflora of the human large bowel. Gut 53: 1610-1616.

Larsen, N., Vogensen, F.K., van den Berg, F.W.J., Nielsen, D.S., Andreasen, A.S., Pedersen, B.K., Abu Al-Soud, W., Sorensen, S.J., Hansen, L.H. and Jakobsen, M., 2010. Gut microbiota in human adults with type 2 diabetes differs from non-diabetic adults. PLoS One 5.

Ley, R.E., Bäckhed, F., Turnbaugh, P., Lozupone, C.A., Knight, R.D. and Gordon, J.I., 2005. Obesity alters gut microbial ecology. Proceedings of the National Academy of Sciences of the United States of America 102: 11070-11075.

Li, X.J., Piao, X.S., Kim, S.W., Liu, P., Wang, L., Shen, Y.B., Jung, S.C. and Lee, H.S., 2007. Effects of chito-oligosaccharide supplementation on performance, nutrient digestibility, and serum composition in broiler chickens. Poultry Science 86: 1107-1114.

Lin, Y., Vonk, R.J., Slooff, M.J., Kuipers, F. and Smit, M.J., 1995. Differences in propionateinduced inhibition of cholesterol and triacylglycerol synthesis between human and rat hepatocytes in primary culture. British Journal of Nutrition 74: 197-207.

Lucio, M., Fekete, A., Weigert, C., Wagele, B., Zhao, X.J., Chen, J., Fritsche, A., Haring, H.U., Schleicher, E.D., Xu, G.W., Schmitt-Kopplin, P. and Lehmann, R., 2010. Insulin sensitivity is reflected by characteristic metabolic fingerprints - A Fourier transform mass spectrometric non-targeted metabolomics approach. PLoS One 5.

Lundell, A.C., Adlerberth, I., Lindberg, E., Karlsson, H., Ekberg, S., Aberg, N., Saalman, R., Hock, B., Steinkasserer, A., Hesselmar, B., Wold, A.E. and Rudin, A., 2007. Increased levels of circulating soluble CD14 but not CD83 in infants are associated with early intestinal colonization with Staphylococcus aureus. Clinical and Experimental Allergy 37: 62-71.

Macpherson, A.J. and Uhr, T., 2004. Induction of protective IgA by intestinal dendritic cells carrying commensal bacteria. Science 303: 1662-1665.

Mandard, S., Zandbergen, F., van Straten, E., Wahli, W., Kuipers, F., Muller, M. and Kersten, S., 2006. The fasting-induced adipose factor/angiopoietin-like protein 4 is physically associated with lipoproteins and governs plasma lipid levels and adiposity. Journal of Biological Chemistry 281: 934-944. 
Massimino, S.P., McBurney, M.I., Field, C.J., Thomson, A.B.R., Keelan, M., Hayek, M.G. and Sunvold, G.D., 1998. Fermentable dietary fiber increases GLP-1 secretion and improves glucose homeostasis despite increased intestinal glucose transport capacity in healthy dogs. Journal of Nutrition 128: 1786-1793.

Maurer, A.D., Chen, Q., McPherson, C. and Reimer, R.A., 2009. Changes in satiety hormones and expression of genes involved in glucose and lipid metabolism in rats weaned onto diets high in fibre or protein reflect susceptibility to increased fat mass in adulthood. Journal of Physiology 587: 679-691.

Maurer, A.D. and Reimer, R.A., 2011. Maternal consumption of high-prebiotic fibre or protein diets during pregnancy and lactation differentially influences satiety hormones and expression of genes involved in glucose and lipid metabolism in offspring in rats. British Journal of Nutrition 105: 329-338.

Medzhitov, R. and Janeway, C.A., Jr., 1997. Innate immunity: the virtues of a nonclonal system of recognition. Cell 91: 295-298.

Medzhitov, R. and Janeway, C.A., Jr., 2002. Decoding the patterns of self and nonself by the innate immune system. Science 296: 298-300.

Mohan, B., Kadirvel, R., Natarajan, A. and Bhaskaran, M., 1996. Effect of probiotic supplementation on growth, nitrogen utilization and serum cholesterol in broilers. British Poultry Science 37: 395-401.

Mohlig, M., Koebnick, C., Weickert, M.O., Lueder, W., Otto, B., Steiniger, J., Twilfert, M., Meuser, F., Pfeiffer, A.F. and Zunft, H.J., 2005. Arabinoxylan-enriched meal increases serum ghrelin levels in healthy humans. Hormone and Metabolic Research 37: 303-308.

Montalto, M., Maggiano, N., Ricci, R., Curigliano, V., Santoro, L., Di Nicuolo, F., Vecchio, F.M., Gasbarrini, A. and Gasbarrini, G., 2004. Lactobacillus acidophilus protects tight junctions from aspirin damage in HT-29 cells. Digestion 69: 225-228.

Musso, G., Gambino, R. and Cassader, M., 2011. Interactions between gut microbiota and host metabolism predisposing to obesity and diabetes. Annual Review of Medicine 62: 361380.

Nakajima, H., Suzuki, Y., Kaizu, H. and Hirota, T., 1992. Cholesterol lowering activity of ropy fermented milk. Journal of Food Science 57: 1327-1329.

Neyrinck, A., Possemiers, S., Verstraete, W., de Backer, F., Cani, P. and Delzenne, N., 2010. Interest of chitin-glucan of fungal origin in the control of metabolic alterations inducedby fat diet in mice: involvement of intestinal microbiota. Diabetes and Metabolism 36: A105-A105. Neyrinck, A.M., Bindels, L.B., De Backer, F., Pachikian, B.D., Cani, P.D. and Delzenne, N.M., 2009. Dietary supplementation with chitosan derived from mushrooms changes adipocytokine profile in diet-induced obese mice, a phenomenon linked to its lipid-lowering action. International Immunopharmacology 9: 767-773.

Neyrinck, A.M., Possemiers, S., Druart, C., de Wiele, T.V., De Backer, F., Cani, P.D., Larondelle, Y. and Delzenne, N.M., 2011. Prebiotic effects of wheat arabinoxylan related to the increase in Bifidobacteria, Roseburia and Bacteroides/Prevotella in diet-induced obese mice. PLoS One 6.

Ooi, L.G. and Liong, M.T., 2010. Cholesterol-lowering effects of probiotics and prebiotics: a review of in vivo and in vitro findings. International Journal of Molecular Sciences 11: 24992522.

Parnell, J.A. and Reimer, R.A., 2009. Weight loss during oligofructose supplementation is associated with decreased ghrelin and increased peptide YY in overweight and obese adults. American Journal of Clinical Nutrition 89: 1751-1759.

Piche, T., des Varannes, S.B., Sacher-Huvelin, S., Holst, J.J., Cuber, J.C. and Galmiche, J.P., 2003. Colonic fermentation influences lower esophageal sphincter function in gastroesophageal reflux disease. Gastroenterology 124: 894-902. 
Possemiers, S., Grootaert, C., Vermeiren, J., Gross, G., Marzorati, M., Verstraete, W. and Van de Wiele, T., 2009. The intestinal environment in health and disease - recent insights on the potential of intestinal bacteria to influence human health. Current Pharmaceutical Design 15: 2051-2065.

Pulusani, S.R. and Rao, D.R., 1983. Whole body, liver and plasma cholesterol levels in rats

Qi, L., Rimm, E., Liu, S.M., Rifai, N. and Hu, F.B., 2005. Dietary glycemic index, glycemic load, cereal fiber, and plasma adiponectin concentration in diabetic men. Diabetes Care 28: 1022-1028.

Regand, A., Tosh, S.M., Wolever, T.M.S. and Wood, P.J., 2009. Physicochemical properties of beta-glucan in differently processed oat foods influence glycemic response. Journal of Agricultural and Food Chemistry 57: 8831-8838.

Resta-Lenert, S., Das, S., Batra, S.K. and Ho, S.B., 2011. Muc17 protects intestinal epithelial cells from enteroinvasive $E$. coli infection by promoting epithelial barrier integrity. American Journal of Physiology - Gastrointestinal and Liver Physiology 300: G1144-G1155.

Richelsen, B., Kristensen, K. and Pedersen, S.B., 1996. Long-term (6 months) effect of a new fermented milk product on the level of plasma lipoproteins - a placebo-controlled and double blind study. Eurpean Journal of Clinical Nutrition 50: 811-815.

Rijkers, G.T., Bengmark, S., Enck, P., Haller, D., Herz, U., Kalliomaki, M., Kudo, S., LenoirWijnkoop, I., Mercenier, A., Myllyluoma, E., Rabot, S., Rafter, J., Szajewska, H., Watzl, B., Wells, J., Wolvers, D. and Antoine, J.M., 2010. Guidance for substantiating the evidence for beneficial effects of probiotics: current status and recommendations for future research. Journal of Nutrition 140: S671-S676.

Roberfroid, M., Gibson, G.R., Hoyles, L., McCartney, A.L., Rastall, R., Rowland, I., Wolvers, D., Watzl, B., Szajewska, H., Stahl, B., Guarner, F., Respondek, F., Whelan, K., Coxam, V., Davicco, M.J., Leotoing, L., Wittrant, Y., Delzenne, N.M., Cani, P.D., Neyrinck, A.M. and Meheust, A., 2010. Prebiotic effects: metabolic and health benefits. British Journal of Nutrition 104: 1-63.

Rosenberg, E. and Zilber-Rosenberg, I., 2011. Symbiosis and development: the hologenome concept. Birth Defects Research Part C: Embryo Today 93: 56-66.

Rummel, C., Inoue, W., Sachot, C., Poole, S., Hubschle, T. and Luheshi, G.N., 2008. Selective contribution of interleukin-6 and leptin to brain inflammatory signals induced by systemic LPS injection in mice. Journal of Comparative Neurology 511: 373-395.

Sanz, Y., Santacruz, A. and Gauffin, P., 2010. Gut microbiota in obesity and metabolic disorders. Proceedings of the Nutrition Society 69: 434-441.

Schmidt-Wittig, U., Enss, M.L., Coenen, M., Gartner, K. and Hedrich, H.J., 1996. Response of rat colonic mucosa to a high fiber diet. Annals of Nutrition and Metabolism 40: 343-350.

Schreiber, O., 2010. Microcirculation, mucus and microbiota in inflammatory bowel disease. Acta Universitatis Upsaliensis, Uppsala, 58 pp.

Seth, A., Yan, F., Polk, D.B. and Rao, R.K., 2008. Probiotics ameliorate the hydrogen peroxide-induced epithelial barrier disruption by a PKC- and MAP kinase-dependent mechanism. American Journal of Physiology - Gastrointestinal and Liver Physiology 294: G1060-G1069.

Shimotoyodome, A., Meguro, S., Hase, T., Tokimitsu, I. and Sakata, T., 2000. Short chain fatty acids but not lactate or succinate stimulate mucus release in the rat colon. Comparative Biochemistry and Physiology Part A: Molecular and Integrative Physiology 125: 525-531.

Song, Y.J., Sawamura, M., Ikeda, K., Igawa, S. and Yamori, Y., 2000. Soluble dietary fibre improves insulin sensitivity by increasing muscle GLUT-4 content in stroke-prone spontaneously hypertensive rats. Clinical and Experimental Pharmacology and Physiology 27: $41-45$. 
St-Onge, M.-P., Farnworth, E.R. and Jones, P.J.H., 2000. Consumption of fermented and nonfermented dairy products: effects on cholesterol concentrations and metabolism. American Journal of Clinical Nutrition 71: 674-681. Storey, D., Lee, A., Bornet, F. and Brouns, F., 2007. Gastrointestinal responses following resistant starch. European Journal of Clinical Nutrition 61: 1262-1270.

Takeda, K., Kaisho, T. and Akira, S., 2003. Toll-like receptors. Annual review of immunology 21: 335-376.

Taubes, G., 2009. Prosperity's Plague. Science 325: 256-260.

Thorburn, A., Muir, J. and Proietto, J., 1993. Carbohydrate fermentation decreases hepatic glucose output in healthy subjects. Metabolism-Clinical and Experimental 42: 780-785.

Tien, E.S., Davis, J.W. and Vanden Heuvel, J.P., 2004. Identification of the CREB-binding protein/p300-interacting protein CITED2 as a peroxisome proliferator-activated receptor a coregulator. Journal of Biological Chemistry 279: 24053-24063.

Tilg, H., 2010. Obesity, metabolic syndrome, and microbiota multiple interactions. Journal of Clinical Gastroenterology 44: S16-S18.

Ting, J.P., Lovering, R.C., Alnemri, E.S., Bertin, J., Boss, J.M., Davis, B.K., Flavell, R.A., Girardin, S.E., Godzik, A., Harton, J.A., Hoffman, H.M., Hugot, J.P., Inohara, N., Mackenzie, A., Maltais, L.J., Nunez, G., Ogura, Y., Otten, L.A., Philpott, D., Reed, J.C., Reith, W., Schreiber, S., Steimle, V. and Ward, P.A., 2008. The NLR gene family: a standard nomenclature. Immunity 28: 285-287.

Todesco, T., Rao, A.V., Bosello, O. and Jenkins, D.J.A., 1991. Propionate lowers blood glucose and alters lipid-metabolism in healthy subjects. American Journal of Clinical Nutrition 54: 860-865.

Towle, H.C., 2001. Glucose and cAMP: Adversaries in the regulation of hepatic gene expression. Proceedings of the National Academy of Sciences of the United States of America 98: 13476-13478.

Trautwein, E.A., Rieckhoff, D. and Erbersdobler, H.F., 1998. Dietary inulin lowers plasma cholesterol and triacylglycerol and alters biliary bile acid profile in hamsters. Journal of Nutrition 128: 1937-1943.

Turnbaugh, P.J., Ley, R.E., Mahowald, M.A., Magrini, V., Mardis, E.R. and Gordon, J.I., 2006. An obesity-associated gut microbiome with increased capacity for energy harvest. Nature 444: 1027-1131.

Van den Abbeele, P., Van de Wiele, T., Verstraete, W. and Possemiers, S., 2011. The host selects mucosal and luminal associations of coevolved gut microorganisms: a novel concept. FEMS Microbiology Reviews 35: 681-704.

Venter, C.S., Vorster, H.H. and Cummings, J.H., 1990. Effects of dietary propionate on carbohydrate and lipid metabolism in healthy volunteers. American Journal of Gastroenterology 85: 549-553.

Vijay-Kumar, M., Aitken, J.D., Carvalho, F.A., Cullender, T.C., Mwangi, S., Srinivasan, S., Sitaraman, S.V., Knight, R., Ley, R.E. and Gewirtz, A.T., 2010. Metabolic syndrome and altered gut microbiota in mice lacking Toll-like receptor 5. Science 328: 228-231.

Vos, A.P., M'Rabet, L., Stahl, B., Boehm, G. and Garssen, J., 2007. Immune-modulatory effects and potential working mechanisms of orally applied nondigestible carbohydrates. Critical Reviews in Immunology 27: 97-140.

Walker, A.W., Ince, J., Duncan, S.H., Webster, L.M., Holtrop, G., Ze, X., Brown, D., Stares, M.D., Scott, P., Bergerat, A., Louis, P., McIntosh, F., Johnstone, A.M., Lobley, G.E., Parkhill, J. and Flint, H.J., 2011. Dominant and diet-responsive groups of bacteria within the human colonic microbiota. ISME Journal 5: 220-230. 
Weickert, M.O. and Pfeiffer, A.F., 2008. Metabolic effects of dietary fiber consumption and prevention of diabetes. Journal of Nutrition 138: 439-442. Weickert, M.O. and Pfeiffer, A.F.H., 2006. Signalling mechanisms linking hepatic glucose Wellen, K.E. and Hotamisligil, G.S., 2005. Inflammation, stress, and diabetes. Journal of Clinical Investigation 115: 1111-1119.

Williams, C.M., 1997. Postprandial lipid metabolism: effects of dietary fatty acids. Proceedings of the Nutrition Society 56: 679-692.

Williams, C.M. and Jackson, K.G., 2002. Inulin and oligofructose: effects on lipid metabolism from human studies. British Journal of Nutrition 87: 261-264.

Wood, P.J., Beer, M.U. and Butler, G., 2000. Evaluation of role of concentration and molecular weight of oat beta-glucan in determining effect of viscosity on plasma glucose and insulin following an oral glucose load. British Journal of Nutrition 84: 19-23.

Wu, X.K., Ma, C.F., Han, L., Nawaz, M., Gao, F., Zhang, X.Y., Yu, P.B., Zhao, C.A., Li, L.C., Zhou, A.P., Wang, J.A., Moore, J.E., Millar, B.C. and Xu, J.R., 2010. Molecular characterisation of the faecal microbiota in patients with type II diabetes. Current Microbiology 61: 69-78.

Xiao, J.Z., Kondo, S., Takahashi, N., Miyaji, K., Oshida, K., Hiramatsu, A., Iwatsuki, K., Kokubo, S. and Hosono, A., 2003. Effects of milk products fermented by Bifidobacterium longum on blood lipids in rats and healthy adult male volunteers. Journal of Dairy Science 86: 2452-2461.

Xiong, Y., Miyamoto, N., Shibata, K., Valasek, M.A., Motoike, T., Kedzierski, R.M. and Yanagisawa, M., 2004. Short-chain fatty acids stimulate leptin production in adipocytes through the G protein-coupled receptor GPR41. Proceedings of the National Academy of Sciences of the United States of America 101: 1045-1050.

Yoshida, K., Shimizugawa, T., Ono, M. and Furukawa, H., 2002. Angiopoietin-like protein 4 is a potent hyperlipidemia-inducing factor in mice and inhibitor of lipoprotein lipase. Journal of Lipid Research 43: 1770-1772.

Zaneveld, J., Turnbaugh, P.J., Lozupone, C., Ley, R.E., Hamady, M., Gordon, J.I. and Knight, R., 2008. Host-bacterial coevolution and the search for new drug targets. Current Opinion in Chemical Biology 12: 109-114.

Zhao, X.J., Fritsche, J., Wang, J.S., Chen, J., Rittig, K., Schmitt-Kopplin, P., Fritsche, A., Haring, H.U., Schleicher, E.D., Xu, G.W. and Lehmann, R., 2010. Metabonomic fingerprints of fasting plasma and spot urine reveal human pre-diabetic metabolic traits. Metabolomics 6: 362-374.

Zhou, J., Martin, R.J., Tulley, R.T., Raggio, A.M., McCutcheon, K.L., Shen, L., Danna, S.C., Tripathy, S., Hegsted, M. and Keenan, M.J., 2008. Dietary resistant starch upregulates total GLP-1 and PYY in a sustained day-long manner through fermentation in rodents. American Journal of Physiology - Endocrinology and Metabolism 295: 1160-1166. 
Figure 1. Intestinal section with focus on the effect of a fat diet and a prebiotic treatment on 879 LPS detection, trough TLR-4 and NOD-1. An increased permeability which is caused by the 880 high-fat diet leads to LPS leakage trough the gut wall, PRRs' detection, thus resulting in an 881 inflammatory response.

Figure 2. Schematic overview of the impact of dietary fiber on several parameters involved in 884 energy metabolism. The mechanism of increased viscosity, decreased absorption of 885 nutrients and replacement of available carbohydrates is relevant for the whole 886 887 gastrointestinal tract. 
Table 1. Overview of in vivo and in vitro experiments in which the effect of prebiotics on several parameters involved in fat and sugar metabolism is confirmed. n.r. $=$ not reported.

\begin{tabular}{|c|c|c|c|c|c|c|}
\hline $\begin{array}{l}\text { Signal } \\
\text { molecule }\end{array}$ & Produced by & Function & $\begin{array}{l}\text { Bacteria/bacteria- } \\
\text { related mode of } \\
\text { action }\end{array}$ & Prebiotics & $\begin{array}{l}\text { Experimental } \\
\text { design }\end{array}$ & References \\
\hline GLP-1 & $\begin{array}{l}\text { L-cells in } \\
\text { ileum/colon }\end{array}$ & $\begin{array}{l}\text { Promotes insulin } \\
\text { secretion, } \\
\text { pancreatic e-cell } \\
\text { proliferation and } \\
\text { muscle oxidation }\end{array}$ & $\begin{array}{l}\text { Acetate, propionate } \\
\text { and butyrate }\end{array}$ & $\begin{array}{l}\text { Oligofructose, } \\
\text { lactitol, resistant } \\
\text { starch }\end{array}$ & $\begin{array}{l}\text { Rat and human } \\
\text { studies, STC cell line }\end{array}$ & $\begin{array}{l}\text { (Gee and Johnson, 2005; Cani et al., 2007b; } \\
\text { Cani et al., 2009a; Piche et al., 2003; Zhou } \text { et } \\
\text { al., 2008) }\end{array}$ \\
\hline GLP-2 & $\begin{array}{l}\text { L-cells in } \\
\text { ileum/colon }\end{array}$ & Intestinal barrier & n.r. & Oligofructose & Mice studies & (Cani et al., 2009b) \\
\hline PYY & $\begin{array}{l}\text { L-cells in } \\
\text { ileum/colon }\end{array}$ & $\begin{array}{l}\text { Slows down } \\
\text { gastric emptying }\end{array}$ & $\begin{array}{l}\text { Acetate, propionate } \\
\text { and butyrate }\end{array}$ & $\begin{array}{l}\text { Oligofructose, } \\
\text { lactitol, resistant } \\
\text { starch }\end{array}$ & $\begin{array}{l}\text { Rat and human } \\
\text { studies, STC cell line }\end{array}$ & $\begin{array}{l}\text { (Cani et al., 2009a; Gee and Johnson, 2005; } \\
\text { Parnell and Reimer, 2009; Zhou et al., 2008) }\end{array}$ \\
\hline Ghrelin & $\begin{array}{l}\mathrm{P} / \mathrm{D} 1 \text { cells in the } \\
\text { stomach and e-cells } \\
\text { of the pancreas }\end{array}$ & $\begin{array}{l}\text { Stimulates } \\
\text { appetite }\end{array}$ & n.r. & $\begin{array}{l}\text { Oligofructose, } \\
\text { resistant starch }\end{array}$ & $\begin{array}{l}\text { Rat and human } \\
\text { studies }\end{array}$ & $\begin{array}{l}\text { (Cani } \text { et al., 2007b; Parnell and Reimer, 2009; } \\
\text { Zhou et al., 2008) }\end{array}$ \\
\hline \multirow[t]{3}{*}{ FIAF } & $\begin{array}{l}\text { Liver, adipose } \\
\text { tissue, intestine, } \\
\text { brain, thyroid, heart, } \\
\text { kidney, skeletal } \\
\text { muscles, spleen, } \\
\text { pituitary gland, } \\
\text { hypothalamus, } \\
\text { placenta }\end{array}$ & $\begin{array}{l}\text { Hypothalamic } \\
\text { appetite control, } \\
\text { fat storage in } \\
\text { adipocytes }\end{array}$ & LPS & n.r. & $\begin{array}{l}\text { N1-neuronal cells, } \\
\text { 3T3-L1 cell line }\end{array}$ & (Brown et al., 2009) \\
\hline & & & Propionate, butyrate & n.r. & $\begin{array}{l}\text { HT-29, Caco-2, } \\
\text { HCT-116, HepG2 } \\
\text { cell lines }\end{array}$ & (Grootaert et al., 2011) \\
\hline & & & $\begin{array}{l}\text { Lactobacillus, } \\
\text { Bifidobacterium, } \\
\text { Bacteroides, }\end{array}$ & n.r. & $\begin{array}{l}\text { HT-29, Caco-2, } \\
\text { HCT-116, LoVo, } \\
\text { SW-480 and HepG2 }\end{array}$ & $\begin{array}{l}\text { (Are } \text { et al., 2008; Aronsson } \text { et al., 2010; } \\
\text { Bäckhed } \text { et al., 2004; Bäckhed } \text { et al., 2007; } \\
\text { Grootaert } \text { et al., 2011) }\end{array}$ \\
\hline
\end{tabular}




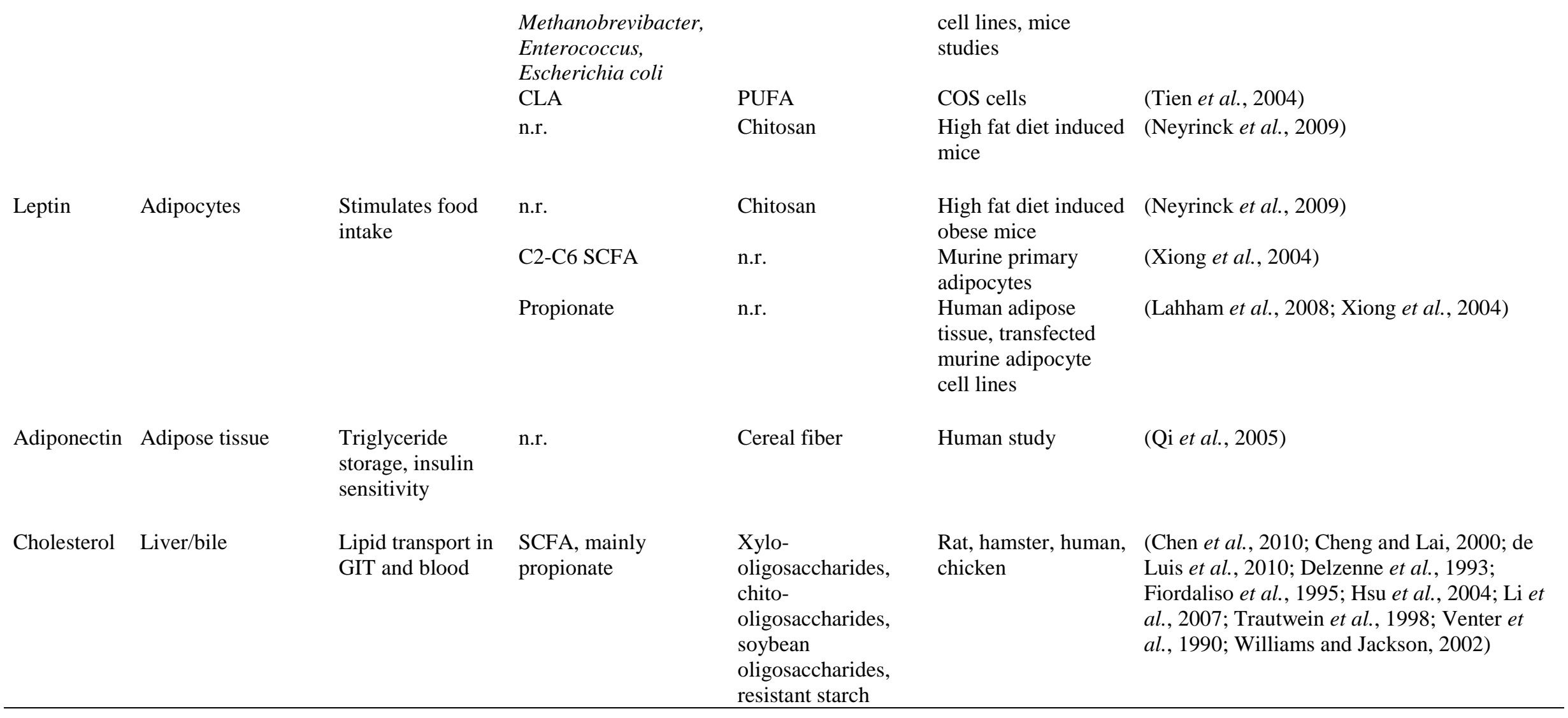

